\title{
Analysis of Financial Policy for the Prevention and Control of COVID-19 in China
}

\author{
Li Liu, Jing Deng ${ }^{*}$, Xue Yu \\ School of Public Health and Management, Chongqing Medical University,-Chongqing, China \\ Email address: \\ 1903141920@qq.com (Li Liu),cqmudj@126.com (Jing Deng),904627564@qq.com (Xue Yu) \\ ${ }^{*}$ Corresponding author
}

\section{To cite this article:}

Li Liu, Jing Deng, Xue Yu. Analysis of Financial Policy for the Prevention and Control of COVID-19 in China. Science Journal of Public Health. Vol. 8, No. 6, 2020, pp. 181-186. doi: 10.11648/j.sjph.20200806.15

Received: November 25, 2020; Accepted: December 9, 2020; Published: December 22, 2020

\begin{abstract}
During the prevention and control of the COVID-19 virus, the Chinese government quickly issued various funding guarantee policies. This study analyzes the financial policies for the prevention and control of COVID-19 in China and understands China's financial support in the field of infectious disease prevention and control. The time limit is from January 22 to June 10, 2020. This study collected 78 national financial policies for COVID-19 prevention and control from the Magic of Peking University database and 9 local early treatment funding guarantee policies for visual statistical analysis. The article conducted an in-depth analysis of the government's financial support from four aspects. One is the financial support method and analyzed the financial responsibilities of the central and local governments in the field of infectious disease prevention and control. It was found that the central and local fiscal responsibilities are not well-distributed and unclear; second, the scope of financial support, the fiscal policy covers all areas, mainly medical treatment; Third, in terms of financial support scale, the outbreak prevention, and control funds have exceeded one-half of China's public health expenditures in recent years, indicating that the normalization of infectious disease prevention and control has insufficient financial support. Fourth, financial support is passive and remedial. This study summarizes the experience of China's financial support policy for COVID-19. At the same time, it provides a reference for other countries in the world affected by COVID-19 to propose effective financial policies for the prevention and control of the epidemic.
\end{abstract}

Keywords: COVID-19, Infectious Disease Prevention and Control, Financial Policy Analysis, China

\section{Introduction}

The rapid spread of the coronavirus disease 2019 (COVID-19) around the world has triggered an unprecedented public crisis. According to the data released by the World Health Organization (WHO), as of June 10, 2020, there were more than 7.14 million confirmed cases of COVID-19 worldwide [1], and its spread rate is fast [2], with widespread impact. It has a huge impact on health and economic systems around the world. The International Monetary Fund (IMF) released the latest "World Economic Outlook" on June 24. The global economy is expected to shrink by $4.9 \%$ in 2020 , and the growth rate of advanced economies in 2020 is expected to be $-8.0 \%$ [3]. According to data from the National Bureau of Statistics of China, China's GDP fell by $6.8 \%$ year-on-year in the first quarter of 2020 , and fiscal revenue fell by $14.3 \%$ year-on-year. Fiscal policy, as an important means for the government to implement macro-control, plays a key role in quickly and effectively responding to the epidemic and maintaining stable economic operation.

As the epidemic intensifies, its destructive effect on the economy is also increasing. Facing the epidemic situation, due to the financial systems and economic conditions of various countries, the fiscal support policies adopted are also different. The US Congress passed the Coronavirus Assistance, Relief, and Economic Security Act, which grants $\$ 1,200$ in subsidies to adults with an annual income of less than $\$ 75,000$, and $\$ 500$ per child. The SME Administration exempts business owners from paying employees Loans for wages [4]. In response to the epidemic, the Japanese government allocated $\$ 454.26$ million for the medical and health system, $\$ 50.75$ billion to ensure interest-free and unsecured loans for small and medium-sized enterprises, and appropriately adjusted the taxes and fees related to individual enterprises and individuals 
to reduce the adverse effects of the epidemic on society and individuals influence [5]. Besides, the European Central Bank launched a pandemic emergency purchase plan on March 18 for COVID-19 treatment and assistance to businesses and individuals to minimize the impact of the epidemic on EU member states [6]. For countries with weak economic strength, such as South Africa, they can only provide weak assistance to a small number of people with formal jobs, and additional economic stimulus plans are unable to carry out [7]. Since the outbreak, the Chinese government has quickly issued a series of financial support policies. New cases of COVID-19 have been maintained at a low level, and resumption of work and production has been progressing in an orderly manner.

Through the analysis of China's financial support policies for COVID-19 prevention and control policy, we can summarize the experience of China's financial support policy. This also has important reference significance for other countries in the world affected by COVID-19 to propose effective epidemic prevention and control and economic operation financial policies.

\section{Method}

This research policy comes from "the magic weapon of Peking University". It is a database containing all legal and policy documents since the founding of China. "the magic weapon of Peking University" has developed into seven retrieval systems including "laws and regulations", "judicial cases", "law journals", "law firm practices", "special references", "English translations" and "magic videos". It comprehensively covers various types of legal information, and is comprehensive in terms of content and functions. It has become an essential tool for leading brands of legal information services and legal workers. The time limit is from January 22 to June 10, 2020. The search was carried out with the keywords of "COVID-19" and "epidemic prevention and control". Then, a total of 78 financial support policies for the prevention and control of COVID-19 were collected at the national level; 9 statistical guarantee policies for the early treatment of new coronary pneumonia were issued in 9 places for visual statistical analysis. The data of new confirmed cases of COVID-19 in China come from the National Health Commission of the People's Republic of China.

\section{Result}

\subsection{Policy Overview}

From the perspective of the main body of policy release, the 77 policy documents mainly include the various departments of the State Council, such as the Ministry of Finance of the People's Republic of China; State Bureaus managed by various departments of the State Council, such as the Civil Aviation Administration of China (CAAC). Mainly composed of various departments of the State Council, the Ministry of Finance participated in a maximum of 29 policy releases, followed by the National Health Commission and the Ministry of Human Resources and Social Security of the People's Republic of China, each with 10 copies. The above-mentioned entities play the roles of fundraising entity, health policy guidance (fund execution entity), and social security in epidemic prevention and control respectively.

The main body of the financial support policy for epidemic prevention and control involves a wide range. Of these 77 documents, 40 were issued jointly, more than half of the relevant documents. Also, in terms of policy effectiveness, 68 of the departmental rules accounted for $88 \%$ of all policies, and administrative regulations, party regulations, and group regulations were 5, 3, and 1 respectively. The number of new financial support policies for the prevention and control of COVID-19 showed an overall downward trend. The peak of policy releases was concentrated in early February, and the number of issued documents reached 24 . At the same time, the number of new confirmed cases of COVID-19 in China reached a peak during the same period, all of which were more than 2,000. With the gradual control of China's domestic epidemic situation, the number of related financial support policies gradually decreased, and the number of policy releases was zero by June. figure 1.

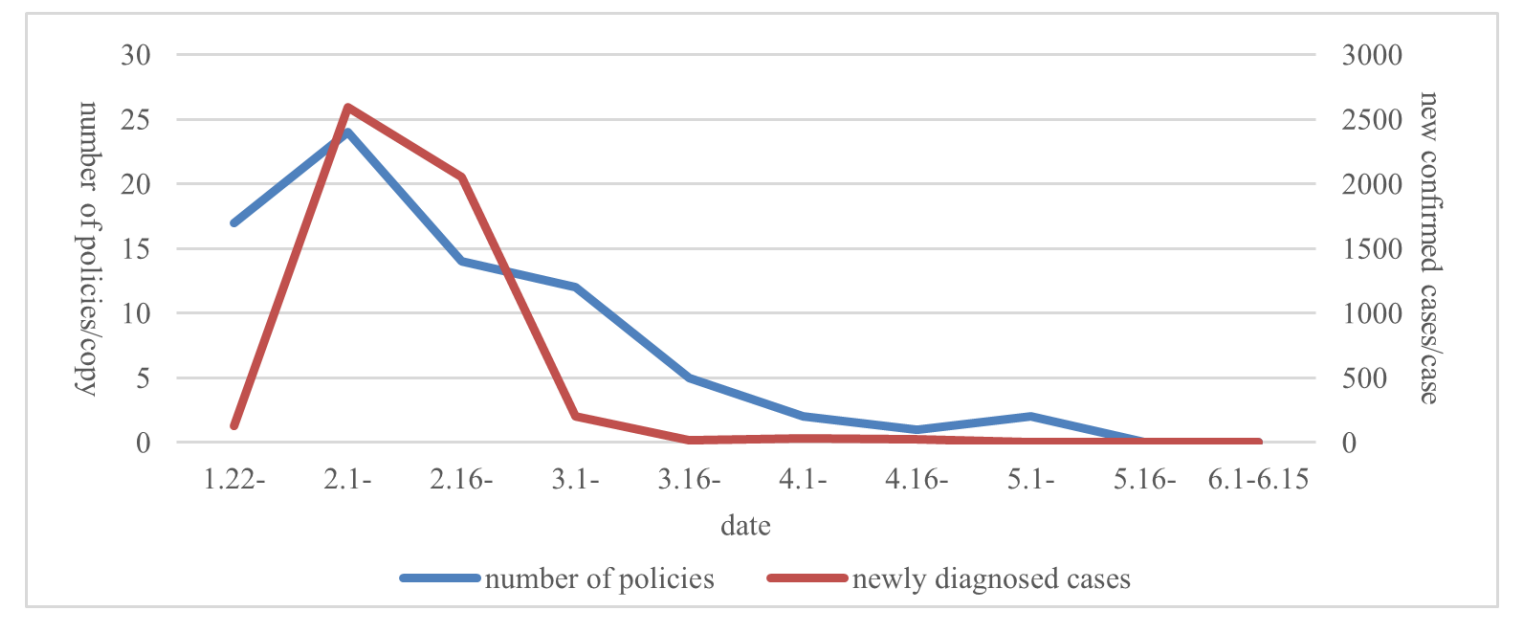

Figure 1. Trends in the number of financial support policies for the prevention and control of COVID-19 and the new confirmed cases. 


\subsection{Policy Characteristics}

\subsubsection{From the Perspective of Financial Support}

China's public health sector adopts a financial input method under the fiscal decentralization system. Among them, basic public health services are jointly undertaken by the central and local finances, and major public health services (national or cross-regional prevention and control of major infectious diseases, etc.) are taken on by the central government. Under the guidance of the Chinese government "to ensure that patients do not affect medical treatment due to cost issues, and to ensure that hospitals do not affect treatment due to payment policies" during the initial stage of COVID-19 [8], the local financial department issued a policy to ensure treatment funds. Provide financial subsidies to patients, medical staff, and medical institutions.

For patients with COVID-19, according to the latest version of the " COVID-19 Diagnosis and Treatment Program (Sixth Edition)" diagnostic criteria ${ }^{(1)}$, it is divided into suspected patients and confirmed patients. The Chinese government adopts different compensation methods according to the classification of patients. The coverage of basic medical insurance in China is stable at more than $95 \%$. For uninsured patients, the medical expenses incurred are guaranteed by financial funds; for suspected patients, medical insurance is first paid, and the personal burden is partially paid by the local government where the medical treatment is located. the central finance will give preferential subsidies depending on the impact of the epidemic situation and local financial situation. For the confirmed patients, medical insurance is still the first payment, and the personal burden is partly financed, and the central and local finances jointly bear the ratio of $6: 4$. However, the localities have shown some differences in further implementing the patient subsidy policy. Guangxi Province and Hubei Province clarified the proportion of provincial and lower-level financial burdens and carried out fund coordination in proportions of $6: 4,6: 4$, or $5: 5$ respectively. In Jilin Province, the provincial finance is the main fund-raiser, and Jiangxi Province is in charge of the

\footnotetext{
"COVID-19 Diagnosis and Treatment Program (Trial Sixth Edition)" diagnostic criteria for suspected patients and confirmed patients: For suspected patients, the judgment is divided into two situations. The first is to have the following epidemiological history, which meets any of the following: (1) Travel history or residence history of Wuhan area or other areas with continuous transmission of local cases within 14 days before the onset of illness; (2) Contact with Wuhan from within 14 days before the onset of illness Patients with fever or respiratory symptoms in the city or other areas where local cases continue to spread (3) there are clusters of morbidity or epidemiological association with new coronavirus infections." Moreover, the following clinical manifestations meet any two: (1) Fever $\left(99.14^{\circ} \mathrm{F}\right)$; (2) With the following imaging features of pneumonia: "In the early stage, there are multiple small patch shadows and interstitial changes, with obvious extrapulmonary bands. Then it develops multiple ground glass shadows and infiltration shadows in both lungs. In severe cases, lung consolidation may occur, and pleural effusions are rare. The second is that there is no clear history of epidemiology, and it meets all 3 of the clinical manifestations. For confirmed patients, one of the following two needs to be met: (1) Real-time fluorescence RT-PCR of respiratory specimens or blood specimens to detect the positive nucleic acid of novel coronavirus; (2) Sequencing of viral genes of respiratory specimens or blood specimens, and known novel coronavirus are highly homologous.
}

finance at the same level (mainly at the county level).

Financial subsidies for medical personnel and epidemic prevention workers are mainly divided into three parts. The first is temporary work subsidies. Based on the approved risk factors and other relevant criteria, the subsidies are \$42.9 and $\$ 28.6$ per person per day, respectively. The subsidy standard for first-line medical personnel in Hubei Province is doubled and fully borne by the central government. The second is the sanitation and epidemic prevention allowance, which is adjusted to $\$ 80.1, \$ 64.3, \$ 50.0$, and $\$ 37.2$ per person per month, compared to $\$ 1.3, \$ 1.0, \$ 0.7$, and $\$ 0.4$ per person per working day in 2004 for categories one to four. The required funds are disbursed according to the current funding channels. The third is wages, and the unit will increase the inclination to the wage performance of the relevant prevention and control personnel according to the prevention and control work. The salaries of medical personnel assisting Hubei Province during the assistance periowd tripled.

The funds for medical and health institutions to carry out prevention and control work are mainly arranged by the finance at the same level (county-level), and the central and provincial finances provide subsidies as appropriate.

\subsubsection{From the Scope of Financial Support}

The Chinese government has adopted corresponding financial support policies for different targets. This study divides policy measures into categories for individuals, enterprises and institutions, and local finance based on the scope of policy beneficiaries. Overall, the financial support policies for enterprises and institutions are the most, 34 $(43.6 \%)$, and the local support policies are at least $14(17.9 \%)$. figure 2 .

The financial support policy measures for enterprises and institutions mainly include tax and fee concessions, financial support, and government procurement, of which the number of financial support policies is the largest (17 copies). Direct financial support measures are mainly focused on providing preferential loans and discount interest support to enterprises. For example, for key epidemic prevention and control enterprises, based on enjoying preferential loan interest rates, the central government grants $50 \%$ discount interest support; undertaking the "Belt and Road" projects of enterprises have provided $\$ 5$ billion in loan support for the resumption of production. The financial support for individuals is mainly subsidized subsidies. The subsidies are mainly for patients and medical personnel. At the same time, subsidies of $\$ 268.84$ million are provided to people in need, and the monthly subsidy is $\$ 6.7$. Among them, the per capita subsidy standard in Hubei Province is $\$ 17.2$ [9]. The policy measures for local finances are also mainly funded, mainly manifested by the fact that the central and provincial finances should be inclined to the grassroots with severe epidemics or weak economies. According to the deployment of the Party Central Committee, from March 1 to the end of June 2020, the increase of 5 percentage points in the use of local financial funds is reserved for the county level to support the "three guarantees" work of 
the grassroots government (guarantee basic livelihood, wages, and operations); The central government has increased the scale of poverty alleviation funds invested in poverty-stricken areas and poverty alleviation projects that have been severely affected by the epidemic.

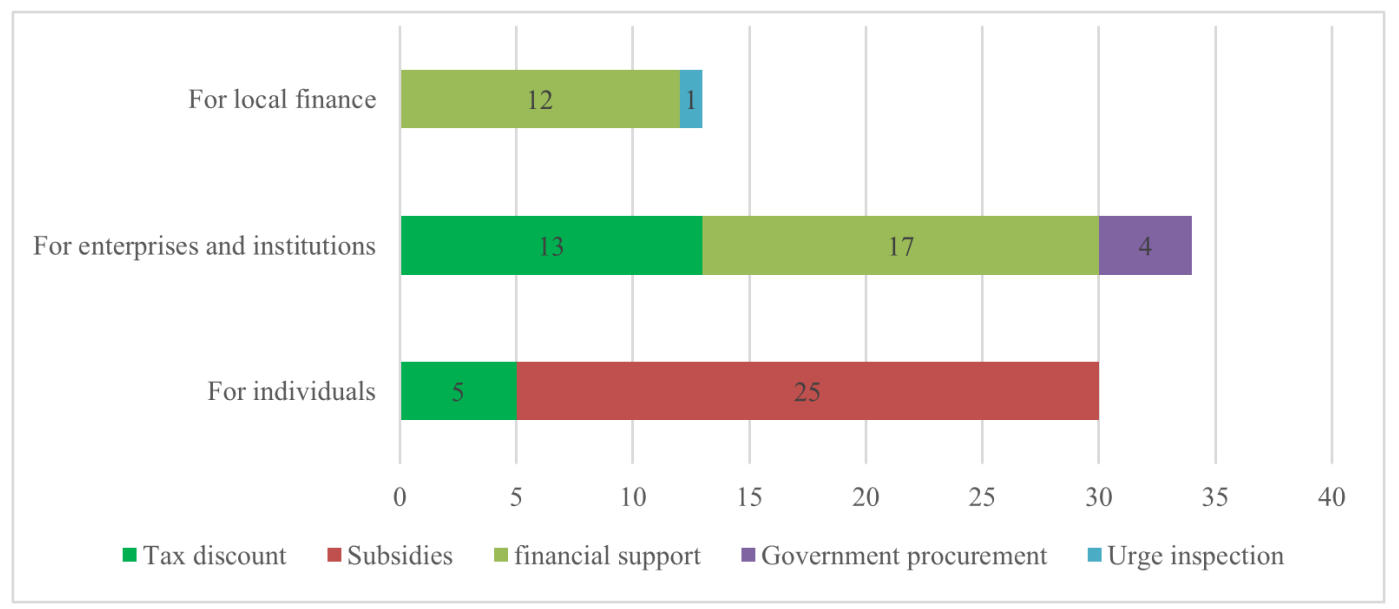

Figure 2. Scope of COVID-19 financial support policies.

\subsubsection{From the Scale of Financial Support}

As of March 13th, China's finances at all levels had accumulatively issued $\$ 16.7$ billion [10], which was used for epidemic prevention and control. The scale of the financial input exceeds one-half of the total public health expenditure (\$29.2 billion) in 2018, and the number of funds required for local support and subsequent economic recovery is even greater. According to the statistics of the Red Cross Society of China, as of March 11th, it received \$27 million yuan in donations and funds for the prevention and control of
COVID-19 [11]. Combined with the analysis of the Chinese government's health expenditures in recent years, it was found that the scale of the Chinese government's health expenditures in 2010-2018 generally showed an upward trend, with an average annual growth rate of $15.88 \%$, but the proportion of GDP in GDP was less than 2\%. figure 3. In 2016, the average level of government health expenditure as a percentage of GDP in the United Kingdom and other developed countries reached $7.7 \%$ [12].

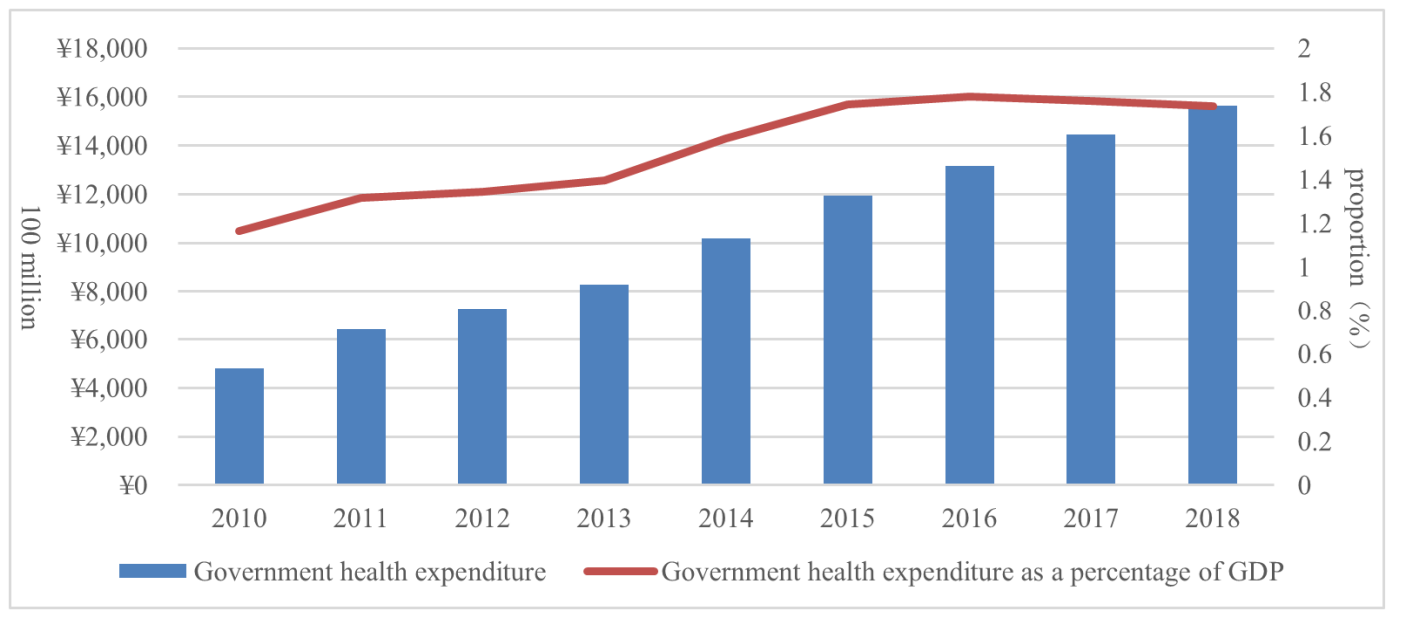

Figure 3. Trend graph of Chinese government health expenditure data from 2010 to 2018.

\subsubsection{From the Timeliness of Government Financial Input}

The COVID-19 disease is the largest major public health incident that has occurred since the founding of China. As of March 13, China's financial authorities at all levels have accumulatively allocated $\$ 16.7$ billion, accounting for $0.49 \%$ of fiscal expenditure in 2019. Coupled with the financial assistance to various industries affected by the epidemic in the later period, China has paid huge costs for the remediation of major epidemics, which is a typical post-mortem remedial input. A similar situation happened before in China. During the SARS period in 2004, to combat the epidemic, various levels of finance raised nearly $\$ 143$ million [13], which accounted for $0.4 \%$ of the fiscal expenditure that year. At the same time, through the analysis of the policy of the prevention and control of COVID-19, it is found that most of them are temporary passive and remedial documents. According to the "Budget Law of the People's Republic of China", "General public budgets at all levels shall set a reserve fee at $1 \%$ to $3 \%$ 
of the general public budget expenditure at this level." However, in the face of a major epidemic, its proportion is low, and it cannot exert its due financial security capabilities [14]. Therefore, government departments have to adopt measures to reduce or adjust other parts of the financial expenditure to support epidemic prevention and control. In the prevention and control of the new coronary pneumonia epidemic, it is required to vigorously reduce general expenditures such as conference training, and the project funds that can be temporarily suspended must be paid back in time.

\section{Discussion}

In this study, the main body of financial support policy is released with the Ministry of Finance, the National Health Commission, and the Ministry of Human Resources and Social Security as the core, coordinating the coordination of other departments. It shows that the problem of epidemic prevention and control has a wide range of impacts, and it is necessary to integrate the resources of various departments and cooperate. Departmental and regulatory policies account for the vast majority $(88 \%)$. Due to their relatively fast procedures for making laws and regulations, they can take timely solutions based on actual problems. Policies that can continue to benefit China's ability to prevent and control infectious diseases in later practice should be retained and further raised to the level of laws and regulations.

The COVID-19 disease is a major national infectious disease, and the central government should bear the responsibility for expenditure in China. For the cost of infectious disease treatment, although the financial support is clear, it is not clear which level of financial support and the specific support plan. The division of fiscal authority is unclear, and the lack of basis for local implementation directly affects the division of responsibility for financial input and the development of prevention and control at all levels of government. At the same time, there are various central and local sharing ratios for different types of patients and different types of subsidies for medical personnel, and the rationality of the division of expenditure responsibilities should be further explored. In the face of sudden public health threats such as major epidemics, the United States, the federal, state, and local governments take responsibility for fiscal expenditures at different levels. When the disaster level exceeds the local fiscal expenditure capacity, they can apply for assistance to a higher level. The federal government has integrated multiple federal agencies and developed various disaster assistance programs, including outbreaks of infectious diseases. In response to an outbreak of infectious disease, the Centers for Disease Control and Prevention (CDC) allocates funds to state and local public health departments. According to the severe situation of the epidemic, local governments can obtain financial support through the Public Health Emergency Response (PHER) and Emergency Management Agency (FEMA). The whole process has clear department cooperation and fund scheduling operation procedures [15]. Therefore, the Chinese government should further refine and standardize the responsibilities of central and local capital input in this regard. Maintain a steady increase in central and local prevention and control guarantee expenditures.

The impact of sudden infectious diseases is large, so the financial support in the prevention and control of infectious diseases should fully consider the parties that may be affected by the epidemic. Support for enterprises should be based on small, medium, and micro-enterprises. Subsidies for individuals should be slanted toward medical groups that are at greater risk of virus infection and poor groups that are at greater economic risk. Similarly, in the face of COVID-19, countries such as Japan and the United Kingdom, in addition to providing tax relief for their domestic SMEs, also provided direct cash subsidies of $£ 3,000$ and up to JPY $¥ 2$ million for each. The Chinese government has not taken any measures to directly release cash to SMEs. At the same time, there are some differences in the coverage of individuals in different countries. Canada and Switzerland provide relief subsidies to specific groups such as the poor and widowed elderly people. Singapore adds cash subsidies to adult citizens and Japan to all citizens [16]. But basically, targeted financial support is adopted based on various factors such as the severity of the epidemic and the characteristics of the main body.

The absolute scale of the Chinese government's health expenditures has been increasing in recent years. However, with the socio-economic development and the rising demand for health services, its share of China's GDP has shown a weak downward trend in the past two years. The proportion of government health expenditures in GDP in developed countries in Germany and Japan has been rising in recent years, reaching more than $9 \%$ in 2016 [12]. Therefore, the scale of the Chinese government's financial input in the health sector still needs to continue to increase. Broaden the sources of financing sources, guide social capital to prevent and control fields through various preferential policies, and increase the share of prevention and health care financial input. Propose a clear and binding effect on the public health financial input level target. Increase support for economic development, improve the level of economic development, and thus increase the scale of prevention and control funding.

The rapid and intensive introduction of a package of safeguard policies for the epidemic, as well as the huge post-epidemic treatment costs and social reconstruction costs, reflects the lack of China's financial input in emergency management for the prevention and control of sudden acute infectious diseases. Japan's approach in this regard is worthy of our reference. Japan has formed a public health emergency budget (proportionally borne by the state and local governments), disaster relief funds, special reserve fees, and an individual multi-level emergency financial security system. The Basic Law on Disaster Countermeasures stipulates that local governments must accumulate as a disaster relief fund by five-thousandths of the local ordinary tax amount for the first three years of the current year, and it must be at least 5 million yen [17]. Therefore, the Chinese government should increase the scale of emergency reserve funds invested in major public 
health emergencies and other public health emergencies, and increase the ratio of provision fees. Pay attention to the establishment of a multi-level emergency fund classification burden system to enhance the ability to respond to major epidemics.

\section{Conclusion}

Through the analysis of China's financial support policy during the prevention and control of the COVID-19 disease, it was found that the government's active fiscal policy played an important role in achieving the staged results of epidemic prevention and control, but also found that China's financial input in the prevention and control of infectious diseases exists some problems. The division of responsibility for central and local fiscal expenditures is unreasonable and unclear. The scale of financial input in the field of infectious disease prevention and control lacks normalized support and insufficient preventive input.

\section{Recommendations}

Therefore, in the next work, the Chinese government will increase financial support for public health, especially the prevention and control of infectious diseases; Led by government finances, establish a three-level material reserve budget system for central, local, medical and health institutions, and enterprises, and clarify financial input responsibilities; Improve the management of reserve funds. All localities draw reserve funds at a rate of $1 \%-3 \%$, and the specific methods of use are stipulated by various levels of finance; The most important thing is to strengthen the evaluation of fiscal policy implementation and use efficiency to improve the performance of fiscal fund use.

\section{References}

[1] World Health Organization (WHO)(2020). Coronavirus dise ase (COVID-19) Situation Report - 142. Retrieved July 13, 2020, from https://www.who.int/docs/default-source/corona viruse/situation-reports/20200610-covid-19-sitrep-142.pdf?sfv rsn $=180898 \mathrm{~cd} 6$.

[2] A, N. Z., A, Z. L., C, S. N. B., A, D. C., \& A, H. Z. (20 20). Epidemiology reveals mask wearing by the public is $\mathrm{c}$ rucial for COVID-19 control. Medicine in Microecology, 4. https://doi.org/10.1016/j.medmic.2020.100015.

[3] International Monetary Fund (IMF). "World Economic Outl ook" update: unprecedented crisis, uncertain recovery. Retri eved July 13, 2020, from https://www.imf.org/zh/Publicatio ns/WEO/Issues/2020/06/24/WEOUpdateJune2020.

[4] Zhang W C.(2020). Analysis and suggestion of fiscal and t axation policies of various countries in response to the pan demic of COVID-19. Financial Supervision., 09: 5-12. doi: CNKI:SUN:CZJD.0.2020-09-003.

[5] Sina Finance Comprehensive. Experience and Enlightenment of Public Health Emergency Management Fiscal Policy in the United States and Japan. Retrieved July 11, 2020, from http://finance.sina.com.cn/roll/2020-05-10/doc-iirczymk07869 12.shtml.

[6] Australian Government Economic Response to the Coronav irus. Retrieved July 16, 2020, from https://treasury.gov.au/c oronavirus.

[7] European Council. Council of the European Union. Report on the Comprehensive Economic Policy Response to the COVID-19 Pandemic. Retrieved July 16, 2020, from https://www.consilium.europa.eu/en/press/press-releases/2020 /04/09/report-on-the-comprehensive-economic-policy-respons e-to-the-covid-19-pandemic/.

[8] Renzaho, A. M. N. (2020). The Need for the Right Socio-Economic and Cultural Fit in the COVID-19 Response in Sub-Saharan Africa: Examining Demographic, Economic Political, Health, and Socio-Cultural Differentials in COVID-19 Morbidity and Mortality. Int. J. Environ. Res. Public Health. 17 (10): 3445. doi: 10.3390/ijerph17103445.

[9] The Peoples Republic of China. Notice on Further Doing a Good Job of Funds Guarantee for New Coronavirus Infect ion Pneumonia Prevention and Control. Retrieved July 11, 2020, from http://www.gov.cn/zhengce/zhengceku/2020-02/1 3/content 5478324.htm.

[10] Hubei Provincial People's Government. Hubei Province Pro vides Price Subsidy of RMB 440 million for People in Nee d. Retrieved July 11, 2020, from https://media.hubei.gov.cn/ 2020/04/10/99160738.html.

[11] The Peoples Republic of China. National financial institutio ns at all levels invested 116.9 billion yuan in epidemic pre vention and control. Retrieved July 11, 2020, from http://w ww.gov.cn/xinwen/2020 03/15/content_5491446.htm.

[12] Red Cross Society of China. Red Cross Society of China accepts the use of new coronavirus pneumonia to prevent and control social donations. Retrieved July 11, 2020, from https://www.redcross.org.cn/html/2020-03/68346.html.

[13] CHEN C Y.(2018) Research on the Current Situation and Countermeasures of Chinese Government Public Health Ex penditure.

[14] WU Y J.(2004) Research on the Reform of Public Finance after SARS. China Health Economy. https://doi.org/10.396 9/j.issn.1003-0743.2004.02.013.doi: CNKI:SUN:WEIJ.0.200 4-02-012.

[15] College of Big Data Application and Economics of Guizhou University of Finance and Economics. Big Data Application and Economics School "Epidemiological Prevention and Control and Local Economic Development" Perspective Series No. 4: Build a long-term financial security mechanism to respond to major public health emergencies. Retrieved July 15, 2020, from http://dsjyj.gufe.edu.cn/f/view-36-876.html.

[16] Bai Y F, Li Y X. (2020). Research on the US Government' s Fiscal and Taxation Policies in Response to Major Disast ers. Fiscal Science (02): 5-16. https://doi:10.3969/j.issn.209 6-1391.2020.02.001.

[17] Wang Yu, Zhang Y L. (2020). Response to the Impact of COVID-19: Global Macro-economic Policy Adjustment and Its Enlightenment. Developmental Finance Research., 1-11. https://doi.org/10.16556/j.cnki.kfxjr.20200507.001. 